\title{
Clinical Follow-up of Conjunctival Malignant Melanoma
}

\author{
Jungbum Choi, MD ${ }^{1}$, Min Kim, MD ${ }^{1}$, Hae Song Park ${ }^{2}$, Sang Yeul Lee, MD \\ The Institute of Vision Research, Department of Ophthalmology, Yonsei University College of Medicine ${ }^{I}$, Seoul, Korea \\ Siloam Eye Hospital', Seoul, Korea
}

\begin{abstract}
Purpose: To investigate the clinical features and course of conjunctival malignant melanoma in Korea. Methods: The medical records of 15 patients, 5 males and 10 females, diagnosed with conjunctival malignant melanoma who had been treated at Severance Hospital from May 1991 to March 2004 were reviewed retrospectively. The clinical parameters of the patients, tumors, and treatment were analyzed for their relation to outcome measures.

Results: The mean age at the time of diagnosis was 53.4 years ( \pm 11.7 years). In all cases, the disease was unilateral and all patients had experienced at least one recurrence. Local lymph node metastasis was found in 3 patients $(20 \%)$ and the mean time to metastasis was 3.5 years. Systemic metastasis was found in 6 patients $(40 \%)$ and the mean time to metastasis was 9.3 years. There were 5 cases of tumor-related death (33.3\%), 4 of which were attributed to systemic metastasis. The Kaplan-Meier estimates of cumulative survival rate were $90 \%$ at 30 months and $56.6 \%$ at 70 months.

Conclusions: Although conjunctival malignant melanoma is a rare disease, it is life-threatening and complete tumor excision at an early stage is mandatory, as is additional therapy to prevent local recurrence and systemic metastasis. Korean Journal of Ophthalmology 19(2):91-95, 2005
\end{abstract}

Key Words: Conjunctival malignant melanoma, Metastasis, Recurrence

Conjunctival malignant melanoma is extremely rare, but when developed can be fatal. The incidence of conjunctival malignant melanoma is $1.6 \%$ of all noncutaneous melanomas. ${ }^{1}$ In 1987, the Swedish National Cancer Registry reported 1,243 cases of new cutaneous malignant melanoma and 70 cases of uveal melanoma, but only 2 cases of new conjunctival malignant melanoma. ${ }^{2}$ In Korea, several cases have been reported, but without any details of progression and treatment. ${ }^{3}$ Hence, we report here the clinical outcome of conjunctival malignant melanoma cases experienced at our hospital.

\section{Materials and Methods}

The medical records of 15 patients who were diagnosed with conjunctival malignant melanoma after biopsy from May 1991 to March 2004 at our hospital were reviewed retrospectively. The age at the time of diagnosis, gender, right eye/left eye, symptoms at the initial period, initial treatments prior to

Received: December 15, 2004 Accepted: March 29, 2005

Reprint requests to Sang Yeul Lee, MD. Department of Ophthalmology, Severance Hospital, Yonsei University College of Medicine, \#134 Shinchon-dong, Seodaemun-gu, Seoul 120-752, Korea. Tel: 82-2-361-8450, Fax: 82-2-312-0541, E-mail: sylee@yumc.yonsei.ac.kr

* This study was presented at the Korean Ophthalmological Society 92th Autumn meeting, Seoul, Korea, October, 2004. the transfer to our hospital, visual acuity, location of lesion, treatment methods, local recurrence, distant metastasis, whether or not exenteration was performed, and death pertinent to tumor were examined. The correlation of local recurrence and distant metastasis to death related to tumor was also examined.

\section{Results}

The average age of the patients at the time of diagnosis was 53.4 years $( \pm 11.7$ years), and all patients were transferred from other hospitals. There were 5 males $(33.3 \%)$, 10 females (66.7\%), 6 right eyes, and 9 left eyes. As for initial symptoms, 9 patients were admitted primarily for lump (60\%), which was the most prevalent symptom, and 1 patient visited a hospital for an expanding nevus. In regard to tumor location, there were 3 cases each of bulbar conjunctiva and palpebral conjunctiva (20\%), 1 of conjunctival fornix, and 8 of simultaneous invasion of the bulbar conjunctiva, palpebral conjunctiva, and caruncle, etc. (53.3\%), which was the most prevalent presentation. Regarding the treatments performed at other hospitals, 12 cases were treated by excisional biopsy as the first treatment $(80 \%)$, which was the most prevalent, followed by 1 case of resection and cryotherapy, and 1 case of incisional biopsy. The treatments performed at our hospital after the transfer were resection in 5 cases $(33.3 \%)$, wide resection and subsequent lid recon- 
Table 1. Summary of descriptive statistics on evaluated baseline study variables in 15 patients with conjunctival melanoma

\begin{tabular}{|c|c|c|}
\hline \multicolumn{2}{|c|}{ Intrinsically categorical variables } & radiation therapy in 2 inoperable cases. Additionally, there \\
\hline \multicolumn{2}{|l|}{ Variables } & cryotherapy and radiation therapy perfomed. The case \\
\hline \multicolumn{2}{|l|}{ Sex } & \\
\hline Male & $5(33.3 \%)$ & wide area. In the case with tumors invading the orbit, orbital \\
\hline Female & $10(66.7 \%)$ & exenteration was considered. However, as the patient refused \\
\hline \multicolumn{2}{|l|}{ Involved eye } & such treatment, only local radiation therapy was performed \\
\hline Right & $6(40 \%)$ & (Tables 1,2$)$. There were 11 cases of local recurrence prior \\
\hline Left & $9(60 \%)$ & to transfer $(73.3 \%)$ and the average number of recurrences \\
\hline \multicolumn{2}{|l|}{ Origin } & was 1.58 times. There were 7 cases of local recurrence after \\
\hline Unknown & $10(66.7 \%)$ & nd the average number of \\
\hline De novo & $1(6.7 \%)$ & e. In all 15 cases, local recurrence was more prevalent than \\
\hline PAM & $1(6.7 \%)$ & once. There were 3 cases of local lymph node metastasis \\
\hline Previous nevus & $3(20 \%)$ & $(20 \%)$, and the mean interval from diagnosis to the \\
\hline \multicolumn{2}{|l|}{ Tumor location } & development of metastasis was 3 years and \\
\hline Bulbar & $3(20 \%)$ & lymph node dissection was performed in 2 of these cases, and \\
\hline Palpebral & $3(20 \%)$ & radiation therapy in one (Table 3 ). There were 6 cases of \\
\hline Fornix (inferior) & $1(6.7 \%)$ & systemic metastasis $(40 \%)$, and the average interval to \\
\hline Combined* & $8(53.3 \%)$ & metastasis was 9 years and 3 months. Regarding distant \\
\hline \multicolumn{2}{|l|}{$1^{\text {st }}$ surgical technique before referral } & metastasis sites, there were 2 cases of metastasis to the nasal \\
\hline Incisional biopsy & $1(6.7 \%)$ & cavity through the nasolacrimal duct (Table 4 ). In the 6 cases \\
\hline Excision & $12(80 \%)$ & with systemic metastasis, 4 patients died. In the case of local \\
\hline Excision with cryotherapy & $1(6.7 \%)$ & recurrence and metastasis in the nasal cavity of the same side \\
\hline No treatment & $1(6.7 \%)$ & local resection was performed and the patient remained under \\
\hline \multicolumn{2}{|l|}{ First treatment after referral } & follow up. In another case, metastasis in the lung was \\
\hline Excision & $5(33.3 \%)$ & \\
\hline \multirow{4}{*}{$\begin{array}{l}\text { Excision with lid reconst. (Mod.Hughes) } \\
\text { Excision with RTx } \\
\text { Excision with Cryo/RTx } \\
\text { RTx followed by Excision } \\
\text { Inoperable case (RTx) }\end{array}$} & $2(13.3 \%)$ & \multirow{2}{*}{ Table 4. Locations of systemic metastasis } \\
\hline & $1(6.7 \%)$ & \\
\hline & $\begin{array}{ll}3 & (20 \%) \\
1 & (6.7 \%)\end{array}$ & Location \\
\hline & $3(20 \%)$ & liver, bone \\
\hline \multicolumn{2}{|c|}{$\begin{array}{l}\text { "Combined: Bulbar and palpebral/bulbar, palpebral and caruncular } \\
\text { involvement. } \\
\text { Cryo: Cryotherapy, RTx: Radiation therapy. }\end{array}$} & $\begin{array}{l}\text { brain, lung, spine } \\
\text { lung } \\
\text { nasal cavity } \\
\text { rib }\end{array}$ \\
\hline
\end{tabular}

struction by the modified Hughes method in 2 cases, local radiation after resection in 1 case, local radiation after resection and cryotherapy in 2 cases, and conventional radiation therapy in 2 inoperable cases. Additionally, there was 1 case transferred without treatment, after biopsy, cryotherapy and radiation therapy perfomed. The case of infeasible complete resection had local recurrence over a wide area. In the case with tumors invading the orbit, orbital (Tables 1 2). There were 11 cases of local recurrence prior to transfer $(73.3 \%)$ and the average number of recurrences was 1.58 times. There were 7 cases of local recurrence after (20\%), and the mean interval from diagnosis to the development of metastasis was 3 years and 5 months. Radical lymph node dissection was performed in 2 of these cases, and adiation therapy in one (Table 3). There were 6 cases of systemic metastasis (40\%), and the average interval to metastasis sites, there were 2 cases of metastasis to the nasal cavity through the nasolacrimal duct (Table 4). In the 6 cases with systemic metastasis, 4 patients died. In the case of local

Table 2. Summary of descriptive statistics on evaluated baseline study variables in 15 patients with conjunctival melanoma

\begin{tabular}{|c|c|c|c|c|}
\hline \multicolumn{5}{|c|}{ Intrinsically numerical scalar variables } \\
\hline Variable & Mean & SD & Minimum & Maximum \\
\hline Age at diagnosis (yr) & 52.8 & \pm 11.67 & 34 & 69 \\
\hline Duration of follow-up (mo) & 32.1 & \pm 38.76 & 1 & 141 \\
\hline Number of prior recurrences before referral & 1.58 & \pm 1.24 & 0 & 5 \\
\hline
\end{tabular}

SD: standard deviation.

Table 3. Clinical course of 3 patients with regional lymph node metastasis

\begin{tabular}{lccc}
\hline & Involved lymph node & Treatment & Survival time from diagnosis (months) \\
\hline Case 1 & Preauricular Cervical & Radiation & 134 \\
Case 2 & Infraauricular Parotid gland & Total parotidectomy \& RND & 70 \\
Case 3 & Preauricular Submandibular & Parotidectomy \& RND & 141 \\
\hline
\end{tabular}

RND: Radical neck dissection 


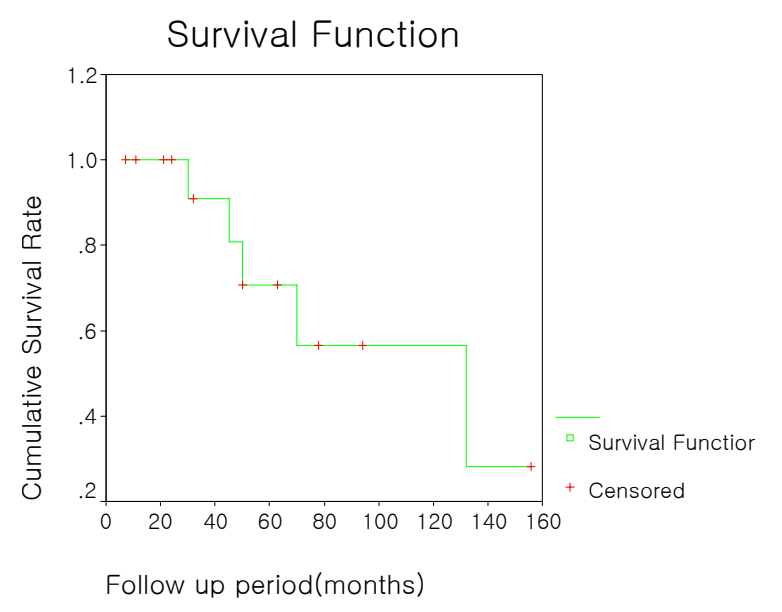

Fig. 1. Kaplan-Meier estimates of survival in 15 consecutive patients with conjunctival malignant melanoma.

confirmed by positron emission tomography (PET) test and the patient remained under follow up. There were 5 deaths related to tumor $(33.3 \%)$, and 4 cases of systemic metastasis. The survival rate related to tumors as predicted by Kaplan-Meier estimate was $90 \%$ survival after 30 months, and $56.6 \%$ survival after 70 months (Fig. 1). During the course, exenteration was performed in 2 cases, one of which developed systemic metastasis and the other patient stopped the treatment voluntarily after local recurrence and subsequently died. Due to the small sample size, it was not possible to examine the statistical significance of the prognostic factors for recurrence and metastasis such as clinical patterns (patient age, gender, tumor origin, location, limbus invasion, tumor size and thickness), initial treatment methods, presence of local recurrence, etc.

\section{Discussion}

Conjunctival malignant melanoma is extremely rare, but may be fatal. Most malignant melanomas are developed in sun-exposed skin, although it also develops rarely in other tissues. Conjunctival malignant melanoma is developed de novo, from an existing nevus or a primary acquired melanosis. The reported incidence has varied widely. The development from primary acquired melanosis has been reported as $9 \%$ by Werschnik and Lommatzsch, ${ }^{6} 57.4 \%$ by Paridaens et al, ${ }^{7} 53 \%$ by Shields CL et al, ${ }^{8}$ and $42.1 \%$ by Anastassiou et al. ${ }^{9}$ The range of reported incidence for the development from existing nevi is $4 \sim 39.1 \%{ }^{4-9}$ The reported incidence for the absence of precancerous lesions ranges from $15.9 \sim 47 \%{ }^{4-9}$ In our study, the incidence was higher in females $(10$ cases) than males (5 cases). Conjunctival malignant melanoma occurs primarily in the bulbar conjunctiva. Shields et al ${ }^{8}$ have reported that among 150 cases of conjunctival malignant melanoma patients, 92\% (138 cases) had the lesion on the bulbar conjunctiva, $3 \%$ in the conjunctival fornix, $4 \%$ in the palpebral conjunctiva, and $0.67 \%$ ( 1 case) each in the plica semilunaris and the caruncle. Werschnik and Lommatzsch ${ }^{6}$ classified the lesion sites as favorable locations (bulbar conjunctiva and limbus) and unfavorable locations (caruncle, fornix, corneal parenchyma, and palpebral conjunctiva). In 85 patients, the lesion occurred in the favorable location for $56.5 \%$ and in the unfavorable location for $43.5 \%$. In our study, the cases invading the bulbar conjunctiva, tarsal conjunctiva and caruncle were the most prevalent ( 8 cases, 53.3\%). Although the prognosis according to location could not be assessed, the survival rate was high in the 3 cases with the lesion limited to the bulbar conjunctiva. However, among these 3 cases, in the 2 cases with local metastasis and systemic metastasis, it appeared that appropriate treatments were performed to increase the survival (Table 3).

The recurrence rate reported in other studies has ranged from $20 \sim 50 \%{ }^{6,8,9}$ In our study, local recurrence was $100 \%$ (all 15 cases) because local recurrence was developed prior to the transfer in most patients (14 cases out of 15 cases).

Histopathological factors pertinent to fatal metastasis have been reported to be tumor thickness and width, epithelioid cells, from presence of atypical melanin cells in case of development from primary acquired melanosis, pagetoid invasion, in situ growth pattern, development in the caruncle and palpebral conjunctiva, reduced small polygonal cells, and mild inflammation and abundant mitoses. $^{4,10}$

Surgical resection is the therapy of choice for conjunctival malignant melanoma. Shields et $\mathrm{al}^{11}$ have reported a complete resection technique by no-touch technique. No-touch technique involves minimal tumor manipulation and partial lamellar scleroconjunctivectomy, to remove the tumor without touching the affected areas. After tumor resection, cryotherapy on the surrounding bulbar conjunctiva is performed. Additional cryotherapy has been reported to prevent recurrence. DePotter et $\mathrm{al}^{12}$ have reported that the only clinical factor associated with distant metastasis is local recurrence, and that local recurrence, in turn, is related to surgical methods. In our study, among 15 cases, resection and cryotherapy were performed in parallel in 1 case (6.6\%) prior to the transfer and in 2 cases $(13.3 \%)$ after the transfer. Werschnik and Lommatzsch have reported two issues demanding attention in the local resection of conjunctival malignant melanoma. First, during tumor removal, even under the microscope, the tumor boundary is not clear. Shields et $\mathrm{al}^{11}$ have reported that tumors could be removed completely by drawing a picture showing the shape and boundary of the tumor with a slit lamp examination prior to surgery and then performing surgery based on the picture. Second, for surgery on the sclera and cornea, tumor cells may be leaked to the globe. To prevent this, they recommended the elimination of tumor cells by treating with alcohol or formalin prior to the surgery and alternatively, the administration of mitomycin eye drops immediately after 
operation. ${ }^{11}$ For cases of difficult primary suture due to wide resection, coverage of the removed area using amniotic membrane was recommended. ${ }^{13}$ The advantages of using amniotic membrane are that, in addition to the rapid wound healing effect, recurrence could be detected readily as the amniotic membrane is transparent. Espana et $\mathrm{al}^{14}$ have reported that for resections larger than $20 \mathrm{~mm}$, treatment with amniotic membrane ensured rapid wound healing and few complications.

It has been reported that even the orbital exenteration of conjunctival malignant melanoma at its early stage did not increase the long-term survival rate. ${ }^{10}$ Hence, orbital exenteration should be considered only when the tumor has invaded the orbit or local recurrence has occurred over a wide area. ${ }^{8}$ In our study, none of the patients were initially treated by orbital exenteration, although in 2 patients, both of whom died, it was performed during the follow up period. Additional known adjuvant therapies are the previously described cryotherapy, radiation therapy, and local treatment with mitomycin eye drops. ${ }^{11,15,16}$

Conjunctival malignant melanoma metastasizes in the preauricular lymph, parotid lymph, and submandibular lymph nodes, dependent on the location of the lesion in the conjunctiva. Esmaeli et $\mathrm{al}^{17}$ have reported the detection of microscopic metastasis of the sentinel lymph node and its appropriate treatment. Amato $\mathrm{M}$ et $\mathrm{al}^{18}$ were able to detect more than 1 sentinel lymph node metastasis by the test using Technetium Tc-99m sulfur colloid pre- and post-surgery. Park et $\mathrm{al}^{19}$ also confirmed the sentinel lymph node metastasis by performing lymphoscintigraphy after surgery in conjunctival malignant melanoma patients. Seppo and Tero ${ }^{20}$ have reported that due to the longer survival period of patients with metastasis only in the lymph nodes at the early period than of patients with systemic metastasis, it was important to prevent systemic metastasis by treating the patients with lymph node metastasis. In the cases of metastasis in the sentinel lymph nodes, radical lymphadenectomy was performed, followed by adjuvant therapies. Adjuvant therapies are local radiation therapy in the vicinity of the lymph nodes, systemic administration of interferon, chemotherapy, and combination therapies. Although the studies on cutaneous malignant melanoma are ongoing, its effectiveness has not been elucidated yet. ${ }^{21-23}$

Lommatzsch et $\mathrm{al}^{24}$ have reported a 10-year local recurrence rate of $24 \%$ and a 10 -year fatality rate of $23 \%$ for metastasis. They also reported that local recurrence and metastasis rates increased with larger tumors. Shields et $\mathrm{al}^{8}$ have reported that metastasis was developed in $14 \sim 27 \%$ of patients, and that $30 \%$ of patients died of metastasis after 10 years. In our study, systemic metastasis was developed in 6 cases $(40 \%)$, with a death rate related to tumors of $33.3 \%$.

On regard to survival analysis, our results showed higher mortality rate than that of previous reports, which may be related to small number of patients and the severe conditions of the lesions when transferred to our hospital.
The shortcomings of our study were the small study population, and the insufficiently detailed information on tumor clinical patterns. Nevertheless, the study demonstrated that the treatment for conjunctival malignant melanoma has not been clearly established. Conjunctival malignant melanoma is extremely rare, but potentially fatal. Hence, it is believed that its survival rate may be improved by the prevention of recurrence and metastasis through complete resection, the early application of adjuvant therapies and the early detection of metastasis in the sentinel lymph node. Future research examining the effect of each clinical pattern on the prognosis with a large study population is required.

\section{References}

1) Scott J, Fraumeni JF, Lee JA. Melanomas of the eye and other noncutaneous sites: epidemiologic aspects. J Natl Cancer Inst 1976;56:489-91.

2) Seregard S, Koch E. Conjunctival malignant melanoma in Sweden 1969-91. Acta Ophthalmol 1992;70:289-96.

3) Kong YT, Kwak YJ, Kim JC, Song DJ. A case of malignant melanoma of conjunctiva. $J$ Korean Ophthalmol Soc 1984;25:235-7.

4) Folberg R, McLean IW, Zimmerman LE. Malignant melanoma of the conjunctiva. Hum Pathol 1985;16:136-43.

5) Norregaard JC, Gerner N, Jensen OA, Prause JU. Malignant melanoma of the conjunctiva: occurrence and survival following surgery and radiotherapy in a Danish population. Graefes Arch Clin Exp Ophthalmol 1996;234:569-72.

6) Werschnik C, Lommatzsch PK. Long-term follow-up of patients with conjunctival melanoma. Am J Clin Oncol (CCT) 2002;25:248-55

7) Paridaens ADA, Minassian DC, McCartney ACE, Hungerford JL. Prognostic factors in primary malignant melanoma of the conjunctiva: a clinocopathological study of 256 cases. Br J Ophthalmol 1994;78:252-9.

8) Shields CL, Shields JA, Gunduz K, et al. Conjunctival melanoma: risk factors for recurrence, exenteration, metastasis and death in 150 consecutive patients. Arch Ophthalmol 2000;118:1497-507.

9) Anastassiou G, Heiligenhaus A, Bechrakis N, et al. Prognostic value of clinical and histopathological parameters in conjunctival melanomas: a retrospective study. Br J Ophthalmol 2002;86:163-7.

10) Paridaens ADA, McCartney ACE, Minassian DC, Hungerford JL. Orbital exenteration in 95 cases of conjunctival malignant melanoma. Br J Ophthalmol 1994;78:520-8.

11) Shields JA, Shield CL, DePotter P. Surgical approach to conjunctival tumors: The 1994 Lynn B. McMahan Lecture. Arch Ophthalmol 1997;115:808-15.

12) DePotter P, Shields CL, Shields JA, et al. Clinical predictive factors for development of recurrence and metastasis in conjunctival melanoma: a review of 68 cases. $\mathrm{Br} J$ Ophthalmol 1993;77:624-30.

13) Paridaens D, Beekhius $H$, Bosh W, et al. Amniotic membrane transplantation in the management of conjunctival melanoma and primary acquired melanosis with atypia. Br J Ophthalmol 2001;85:658-61.

14) Espana EM, Prabhasawat $P$, Grueterich $M$, et al. Amniotic membrane transplantation for reconstruction after large ocular surface neoplasm. Br J Ophthalmol 2002;86:640-5.

15) Lederman M, Wybar K, Busby E. Malignant epibulbar melanoma: natural history and treatment by radiotherapy. 
Br J Ophthalmol 1984;68:605-17.

16) Finger PT, Milner MS, McCormick SA. Topical chemotherapy for conjunctival melanoma. Br J Ophthalmol 1993; 77:751-3.

17) Esmaeli B. Advances in the management of malignant tumors of the eyelid and conjunctiva : the role of sentinel lymph node biopsy. Int Ophthalmol Clin 2002;42:151-62.

18) Amato M, Esmaeli B, Ahmadi MA, et al. Feasibility of preoperative lymphoscintigraphy for identification of sentinel lymph nodes in patients with conjunctival and periocular skin malignancies. Ophthal Plast Reconstr Surg 2003;19:102-6.

19) Park CS, Son JH, Chung WS, Cho IH. Lymphoscintigraphy of eyeball and ocular adnexal malignant tumors. $J$ Korean Ophthalmol Soc 2004;45:893-8.

20) Seppo T, Tero K. Metastatic pattern and survival in disseminated conjunctival melanoma. Ophthalmology 2004;
111:816-21.

21) Kirkwood J, Strawderman M, Ernstoff M, et al. Interferonalpha-2b adjuvant therapy of high-risk resected cutaneous melanoma: the Eastern Cooperative Oncology Group Trial EST 1684. J Clin Oncol 1996;14:7-17.

22) Buzaid AC, Colome M, Bedikian A, et al. Phase II study of neoadjuvant concurrent biochemotherapy in melanoma patients with local-regional metastases. Melanoma Res 1998;8:549-56.

23) Eton O, East M, Legha SS, et al. Pilot study of intra-arterial cisplatin and intravenous vinblastine and dacarbazine in patients with melanoma in-transit metastases. Melanoma Res 1999;9:483-9.

24) Lommatzsch PK, Lommatzsch RE, Kirsch I, Furman P. Therapeutic outcome of patients suffering from malignant melanoma of the conjunctiva. Br J Ophthalmol 1990;74: 615-9. 